\title{
Online professional education: A case study of an MBA program through its transition to an online model
}

\author{
Lynne Schrum, Associate Professor \\ Angela Benson, Graduate Research Assistant \\ The University of Georgia \\ Department of Instructional Technology \\ 604 Aderhold Hall \\ Athens, GA 30602-7144 \\ Phone: 706-548-1304 \\ FAX: 706-542-4032 \\ E-mail:1schrum@coe.uga.edu, abenson@coe.uga.edu
}

\begin{abstract}
Recently a large corporation joined with a large southeastern university's College of Business MBA program to create a distance MBA program uniquely suited to the corporation's high level workers' needs to obtain the degree while they continue working. This corporation invested significantly in the design and development of this tailored program which includes online and face-to-face components. This paper reports on research on the first year of this pilot program from the faculty, administrative, and student perspectives. Conclusions are given and suggestions are made for further research.
\end{abstract}

\section{KEY WORDS}

university-corporate partnerships, online degree programs

\section{INTRODUCTION}

A serious double problem has evolved in business firms: organizations have difficulty retaining competent workers, and yet many individuals need to pursue an MBA degree to successfully compete for higher positions. Currently, many companies sponsor a valuable employee to return to school; however, they typically lose the services of that employee for the two years of schooling. Traditional distance learning has been tried (satellite delivery, for example), with spotty results, especially since many of these busy professionals travel extensively, and are not available on a specific night each week [1], [2]. And at the same time, the workplace is changing and demanding higher skill levels of its workers [3]. Many organizations and universities have turned to technology to solve this problem, especially now that it has evolved to the point where it can provide the needed experiences through electronic networks and groupware [4], [5].

A recent study of post-secondary distance education institutions, conducted by the National Center for Education Statistics [6], presented current trends. They used the definition of distance as education or training courses delivered to off campus locations via audio, video, or computer technologies. The study found that one third of the institutions offered distance education courses, another quarter planned to offer courses in the next three years, while 42 percent did not offer and did not plan to offer such courses. To put it in perspective for this project, Peterson's [7] recently reported that over one hundred institutions offer graduate business education via distance learning. 
Further, the technological advances in computer networks have increased the expectations for student success in distance learning environments. Groupware (a new class of software that supports synchronous and asynchronous interactions), like Lotus LearningSpace, is currently being used to provide networked learning environments that facilitate collaboration and interactivity among students [8].

Recently a large corporation joined with a large southeastern university's College of Business MBA program to create a combined model uniquely suited to the corporation's high level workers' needs to obtain the degree while they continue working. This corporation invested significantly in the design and development of this tailored program. Further, although many institutions are experimenting with online education, little is known about the professional development of the faculty to prepare and plan for the transition to this new environment. This paper reports on research during the first year of this program from the faculty, administrative, and student perspectives.

The questions that guided this study included:

?? In what ways did faculty planning accommodate the online components of this MBA program?

?? What did faculty identify as the challenges in accomplishing the organizational, pedagogical, and institutional tasks of teaching in this way? What did students identify as challenges to learning in this new environment?

?? What were the unanticipated and serendipitous results of this combined face to face and online model?

\section{DATA SOURCES AND METHODS}

A case study approach is an appropriate manner in which to investigate evolving phenomena, particularly in situations in which the participants' understandings of the processes are of primary importance[9]. Participants in this study included the MBA faculty, administrators and project director, and students. Qualitative methods included semi-structured interviews with select participants, electronic and on-site observations, focus groups with students and faculty, and analysis of transcripts of faculty discussion (electronic and face to face). The semi-structured interviews were conducted using naturalistic inquiry. Written (electronic and non-electronic) responses to queries were also included for clarification.

The utilization of multiple methods was designed to triangulate the research perspectives and increase the understanding of the participants' perspectives and response to the activities [9], [10], [11]. Efforts were expended to triangulate the data sources, and to include all possible opportunities to understand the experiences from as many perspectives as possible; these included analysis of written documents and group discussions, individual perspectives, and community memories.

All interviews, individual and group, were audio recorded, and then transcribed. Data analysis included open coding of all transcripts by the researchers individually, and then together to compare and discuss the findings and their meanings. As themes emerged from the data, researchers constructed team case study reports, content analysis of the observations, interviews, and construction of cross case analysis models where appropriate. Two researchers connected to the project served as debriefers for the analysis components. These research activities represented a challenge for traditional research methods, especially considering that conducting research using ethnographic techniques via an electronic format is a fairly recent possibility which requires special attention to ethical issues [12]. 


\section{BACKGROUND}

Ten faculty members of the college of business were invited to participate in the creation of an integrated, multiple technology, combined format, online MBA program. The corporation, interested in providing developing opportunities for its employees, promised to fund and support its chosen participants, and the planning began. The project was designed for a cohort of 46 successful executives to complete the MBA in an intense two-year format.

The first semester of the program, October 1998 through January 1999, began with the 46 students enrolled in five semester-long courses. After an intensive, two-week face-to-face session on the university campus, during which the students were introduced to each other, their instructors, the coursework, and the program's distributed format, the students returned to their busy lives as corporate executives assigned to various projects throughout the United States and Canada. They continued their studies through a variety of distance technologies centered around the courseware system, Lotus LearningSpace.

Five components distinguish the program development efforts: specialized curriculum, student workload management, mixed delivery mode, ongoing evaluation, and support.

\section{A. Specialized curriculum}

The business school and the corporation agreed on a specialized curriculum that would meet the needs of the corporation's employees. At the program level, the specialized curriculum limits students to two paths of study, finance or marketing, while on-campus students have more options. Specialization reaches the course level as well, with the knowledge that the program content must still meet accreditation standards. According to the program's administrative assistant in a March 1999 personal interview,

The accounting course, for example, was originally designed as two courses, financial accounting and managerial accounting, and we combined those two into one class. . We can alter these courses to a certain extent but for the program to be an accredited MBA from [the business school] it has got to contain these things.

\section{B. Student workload management}

The business school and the corporation tried to balance the school and work demands of the students, who remained full-time employees throughout their tenure in the program. The business school faculty agreed to keep the students' school study time to 15 hours per week when they're off-campus and the corporation agreed to limit their normal work week (sometimes as much as $70-80$ hours) to 40 hours.

\section{Mixed delivery mode}

The business school and the corporation agreed that the distance MBA program would include face time and distance time. Each course includes a face-to-face component equaling $50 \%$ of the face time of a traditional MBA course, and a distance component equaling the remaining $50 \%$ plus the study time normally associated with the course during a typical semester. A program administrator used the Statistics course to show the division of hours, "For example, Stats is a two-hour class and gets a total of sixteen face hours and sixty distance hours." The face-to-face hours are accomplished during the two-week initial face-to-face session, and subsequent weekend campus visits, one approximately every three months.

\section{Ongoing evaluation}

Ongoing evaluation has been a major part of the program. Students provided anonymous, weekly online feedback of their program experience, reporting the amount of time spent on assignments as well as any problems they encountered with the program. Program faculty and administrators viewed this data each 
week and decided how to best meet the concerns. To deal with student complaints that assignments were grossly exceeding the specified time parameters, the program employed an on-campus MBA student to benchmark the course assignments. This student completed the assignments and reported the time required. As a result of the benchmarking, one professor concluded that his course should be a three-hour course instead of a two-hour course, and he petitioned to get the change made.

\section{E. Support}

The program maintained a support staff of three full-time employees and nine graduate assistants to serve both faculty and students. The support team was responsible for initial training and on-going support. During the summer preceding program start-up, three full-time interns were employed to support the training efforts.

\section{FACULTY PERSPECTIVES}

The faculty involved in this project could be described as having an enormous amount of energy and enthusiasm. In this program, unlike some implementations of innovative practice, time was devoted to support issues prior to the launch of the program. The faculty interviews and surveys identified four categories of perspectives: Process, Instruction, Interaction, and Current Concerns.

\section{A. Process}

Planning for an October 1998 implementation began early the spring before with selection of faculty and support personnel. From an early survey, 75 percent of the those chosen had little to no experience with online learning, either as a teacher or a learner. Rather, those who volunteered, or who were chosen, had reputations as excellent teachers, and had demonstrated some characteristics of collaboration and willingness to accept a challenge. The rewards for their participation included summer financial support, new laptop computers, valuable technological support and assistance, and course reduction during the first year. In exchange, each faculty member was expected to commit time and energy toward the reconceptualization of his/her course. The attitude of one demonstrated the view of these professors, 'I am nervous and eager to get started but have a few major problems to articulate in my mind before I develop a detailed solution and implementation plan."

Two processes were started during that summer prior to the start of classes. First, a month long seminar was designed, and the ten faculty attended. Faculty members were responsible for a variety of tasks. They learned about the capability of the software, from student and faculty perspectives, and began to work individually and together to transform their subject matter and traditional teaching experiences to an online format. A consultant was brought in to offer assistance in online pedagogical issues, and faculty had time to work with technical support personnel on the specifics of their courses. One hundred percent of the faculty felt that they received more personal and technical support than they had anticipated.

At the same time, a weekly meeting was established for the faculty team. These meetings, called Customer Quality Assurance meetings, allowed faculty time to discuss current issues, collaborate on course experiences, and address student concerns that had surfaced during weekly online feedback. They also used these meetings as a checkpoint to identify students who were having problems in one or more courses.

\section{B. Instruction}

As important as the technical and support issues were, most faculty were more focused on the instructional aspects of their courses. Their concerns were thoughtful and realistic. One faculty member summarized, 
The online/distance-learning aspect of the program has gone extremely smoothly, largely because of the extraordinary support we've received for equipment, training, and technical support during the semester. The more difficult part is the part-time aspect how to create a self paced schedule that's feasible for busy employees yet also satisfied the requirements of a rigorous degree program.

The concern for providing appropriate and useful instructional experiences overshadowed all the other concerns. Faculty members were unsure about the best way to proceed in creating this online experience. Some tried hard to "convert as much as I possibly could the existing class I was teaching for the MBA program to the [online]." Others approached it differently, and found themselves "re-thinking what is the course and what is my role. And I think what I did rather than sharing knowledge was more I created learning opportunities for them. I had not had that focus before." And still another commented that he tried to remember that these students were "remote learners rather than try to give them a distance learning version of exactly what they would have gotten on campus."

Additionally, some subjects were viewed as less successful than others in the online environment. As one professor put it, "Some of it [unhappiness with the course] was directly due to the fact that I was teaching statistics because you get oodles of questions about things that are difficult to explain through distance learning or through the phone. You can't explain formulas over the phone." Another agreed,

For some of the accounting, statistics, economics, those are not really subjects that lend themselves to self-paced, case-based teaching as much as legal studies or MIS. It seems that a lot of the distance learning software and distance learning concepts seem to be more oriented toward these types of courses.

Even as a difficulty was being identified, the faculty began to think about solutions. For example, "One of the biggest challenges was that the class had to be "one size fits all" so it was too basic for several students but probably too challenging for a few. Perhaps we need to allow some students to test out of classes..."

Overall, the reaction to teaching their courses online has been extremely positive. One member of the faculty said, "The 15 hours I had were the most fun I've had teaching. I believe this is because of the experience base of these students and the fact that they have the commonality of being from the same company."

\section{Interaction}

The nature of interacting with the students and having the students interact with each other was a major goal of the faculty. The two week face to face orientation was considered a chance to get to know each other, and to establish relationships. This did not work as well as expected. One faculty member met every day with the group to begin his class. He commented, "So I got to know name, face, and personalities pretty well, though not everyone. What surprised me was how little that carried over into the distance part. You might think that it would be the opposite."

It was decided that they would all use threaded discussion rooms as a way to promote thoughtful and reflective discussion. This did not produce the desired results in every circumstance. Professors commented that students often read their questions, and then responded, without reading the responses of other students, resulting in a linear commentary, rather than a discussion. It was decided that this tool was useful for some activities and some subjects, specifically those based on case studies or ethical issues, and that it should be used only when appropriate. As the student comments will demonstrate, the real interaction appeared to occur between one student and one professor as necessary, and among small group team members. 
The faculty wanted to ensure that students were learning, but also that they were comfortable in the electronic communications. Another goal surrounded their own comfort and satisfaction with the teaching process and getting to know their students. One professor verbalized this anxiety and concern,

Part of the reason you all think I am a good teacher is being taken away - the connection [with students in face to face]. If you were to line these up right now, I would know only a few names, and I always pride myself that by the end of the quarter I know them all.

\section{Current concerns}

The number one concern of faculty members was the amount of time that it took to do a good job. One professor said, "I think it worked better than I would have ever expected. However, I have to say it was not without a cost, and the cost was that I spent 40-60 hours a week for a two hour course." Many of the others were concerned that they simply could not expend that amount of time on any one of their many daily responsibilities.

\section{STUDENT PERSPECTIVES}

Students were selected for the program in a two-step process. The corporation's employees selfnominated for the program and the management selected the top candidates to apply for the 46 seats reserved for the program. The candidates then applied to the college and were subjected to its rigorous admission standards. These students were willing to tackle the challenge of working very hard for two years in order to earn this degree, and to have the support of their employer while they did so.

The interviews and surveys conducted with the students resulted in five categories: Initial Concerns, Faculty Responsiveness, the Distance Component, Team Focus, and Program Content.

\section{A. Initial Concerns}

Though more than $75 \%$ of the students said they could handle the 15 -hour a week course load, they entered the program in October 1998 concerned about their ability to be successful. Of the 46 students surveyed, 35 expressed concern with their ability to balance school work, the job, and their personal lives. As one student reported, "[My concern is] balancing work responsibilities (e.g., various committees, coaching, etc) and this program and still have time for some sort of 'life'." Fear of the isolation, loss of student and instructor interaction, level of academic rigor, and level of personal preparation for program, to a much lesser degree, were also cited as concerns.

The student concerns were proven valid within the first month of the program. The expected 15-hour weekly coursework turned into 20-30 hours for many students. As one student said, "The 15 hours required, generally that's not enough to keep you up. The people that seem to be keeping up are generally running a little over 20, 25 hours."

The unexpected time requirement impacted their work and family lives, and caused the students much personal stress. Students found that they had to "make choices to do things and not do other things." As one student wrote, "My priorities are family, work, and school, in that order. If I have to turn in an assignment late, that is okay if I am working on one of the higher priority areas." The one area where students felt they could not cut back was on their team work. "I find that I pay more attention to anything that is team-oriented because I don't want to let my team down. . .I'm willing to let my own thing [individual assignments] go, but not the team thing."

The students adopted a variety of strategies to deal with the course load. They found study time while 
waiting in airports, riding in cars, and between meetings. As one student said, "I actually commute an hour a day in the car. So a coping strategy for me is to stick my computer in the passenger seat and listen to [the professor's] lecture while driving in." Students also found leveraging individual team member strengths when completing team assignments an effective strategy. One student said about team assignments, "We started out, one person had each subject but some of the classes had a lot more group activities than others so we had to change." Another said, "We have somebody take an initial cut of the assignment." The downside, the student continued, is "if somebody else did the initial cut you have a tendency not to understand it [the course material] as well."

The students' attitudes about grades seemed to help them cope with the intense course load as well. Most students "don't give a dog gone about grades. In fact, that in and of itself takes the pressure off." One student's experience was shared by many others, "I went through high school and college just trying to pass and get an A and move on. And this is so wonderful because I'm here to learn and to gain knowledge and apply it and it's much more meaningful to me. I'm not just trying to get an A. I'm trying to think."

\section{B. Faculty Responsiveness}

Most students cited faculty responsiveness as a positive component of the program. "The professors and staff have been absolutely wonderful about adjusting the workload and assignments" in response to student reports in the weekly, online program evaluations. In response to the students' concern about managing five or six classes over the course of a single semester, the second semester course model changed from five or six courses per six-month semester, to two courses per three-month term. The students' response to the new model was captured in one student's words,

I definitely prefer the approach of having fewer courses, that only last about 3 months (obviously with a lot of work going on in those 3 months!) rather than a course that has the same amount of work but is distributed across 6 months. There are several reasons. 1) Psychological. It always feels good to finish a course and gives me a sense of accomplishment. When the course lasts a long time this is not as clear cut. 2) It is easier to manage the schedule when we only have to track a few things rather than 4 or 5 courses at once.

The program administrative assistant recalled, "I drew this [the new model] up and showed it to them and they clapped for about a minute. It was amazing."

\section{The Distance Component}

In general, the students felt that some courses worked better as distance courses than others. As one student said,

I know from a Statistics perspective I would learn a lot more from sitting around a table with four people going how did you get there, why did you even think to start there, rather than [discussing the subject at a distance]. . .So I think there are some subjects that lend themselves better to distance learning than others where you can actually combine views and discuss them.

For example, "Legal [was] great for teams because you get on a conference call and in twenty minutes you could talk about the issues. Someone would take minutes and then summarize and then you give feedback on their summary..."

Though some students found the online threaded discussions useful, many reported the time to read through all the messages from 45 students (one dropped the program in early January) time-consuming 
and burdensome. One student reported,

The Course Room threads have been very ineffective. When I try to 'keep up' with them, I find myself spending a lot of time reading everyone else's comments. . .I find that the comments placed out there are not the type of 'discussion comments' I expected. Instead, they seem to be mini-essays. My frustration has led me to just simply ignoring the bulk of the comments.

Additional student comments suggest that the effectiveness of the online discussions was related to how they were used by the instructors. In general, students found the requirement to participate in the online discussions ineffective. One student reported,

I don't agree that contributions to the courseroom should be mandatory or heavily weighted as that seems to encourage some individuals to go way overboard. I would like to see the instructors help initiate the discussions and then let those in the class who are interested participate if they choose.

A second student agreed, and suggested that professors were using participation in online discussions as the wrong measure of student engagement in the course,

It bothers me to no end that somehow profs don't think we are "participating" because we haven't posted something on every single topic. I understand that the profs want to know we are alive without making everything an assignment, but at the same time the lack of "connection" is one of the prices to be paid for doing long distance learning.

\section{Team Focus}

The 46 students were divided into 11 teams and students were given individual as well as team assignments. Overall, the students seemed to feel that the teams were very effective. When asked about the most effective component of the program, one student said, "Group work - getting a different perspective on group assignments has been very valuable. Also, I can't imagine doing this program without the emotional and spiritual support of my team." The primary mode of communication for the teams was their weekly team conference calls.

\section{E. Program Content}

For the most part, students found the course content directly applicable to their daily work lives. "The assignments and topics of study are very relevant to my day to day work. Many of the issues that I deal with at work everyday are similar to the things I am studying," said one student. Even those who didn't find direct application of the content found their "awareness raised" by the courses they took. One student said about the Legal course,

Legal was the best example of an exciting, thought-provoking, creative new learning experience for me. The team assignments facilitated interesting intellectual discussion, the courseload was fair, and I found myself excited about reading and learning everything; I learned so much, and spent a lot of time thinking about how much the topics that we learned about affected my life, both personally and professionally.

\section{RESULTS/CONCLUSIONS}

This paper presented the results of research on the first year of an innovative program to create a hybrid online MBA program for busy executives from one organization. It provided the thoughts and understandings from the perspectives of the faculty, administration, and students as they all struggled to 
adapt to this effort. Overall, the program's commitment to technical support and ongoing improvement differentiates it from other similar programs which suffer due to lack of integrated planning, sufficient technology support, and time [8].

Faculty cited program support, initial technical and pedagogical training as well as the ongoing support, as a major factor in their success as program instructors, while students cited the responsiveness of the faculty and administration to student concerns as a key factor in their success. The ability of the students to react honestly to their experiences, and most particularly, the willingness of the faculty to respond and adapt, has been one of the most important aspects of the program. Working together as a team, the students, faculty, and administrators of the program have made enormous progress in establishing effective ways of teaching and learning in the distance environment.

Changing the nature of traditional MBA programs is a non-trivial task. Faculty have had an especially difficult time changing the ways in which they teach, regardless of their own personal use of electronic media [13]. In an electronic environment the role of faculty changes in many ways, and in particular, they must give up some control of the classroom environment. They are forced to develop and design their activities and interactions in new ways, and they may be frustrated without the ability to recognize students' furrowed brows. These challenges go far beyond the need to be comfortable with just the reliance on technology to support their courses [8]. The new paradigm requires team teaching, reallocation of limited resources, and ongoing dialogue for planning, as well as translating the group processes used for student work to that of faculty [14], [15].

The experience of the faculty in this program provided insight for other faculty moving to the world of online teaching and learning. Because their support needs were met satisfactorily, the faculty were able to direct their energies to providing effective learning experiences for the distant students. With appropriate technical and pedagogical support, they experimented with course design and allowed course design to evolve as they received feedback from their students. Some faculty found value in translating attributes of their online course design to their traditional face-to-face courses. While faculty considered their online experience a positive one, the experience was not without cost. The first cost was the time required to support the courses and the students. The second was their loss of traditional classroom cues and feedback.

The student perspectives and experiences which emerge from this study highlight the factors contributing to student success in the networked classroom. First, like all part-time students, the students in this program struggled to balance their course work with full-time jobs and their personal lives. They learned to convert any down time in their daily schedule into study time. Many made short-term sacrifices in their personal and professional lives so that they would be able to reap the long-term benefits of having an MBA degree. Second, the students had to adapt to a distance learning environment. The individual course rooms, which had been expected to promote student interaction, did not have that effect for the students, who cited their weekly conference calls with team members as their greatest source of support and interaction. In addition, students recognized that some courses worked better in a distance environment than did others, just as they found that some activities were better completed as a team while others were much more easily and appropriately accomplished individually.

This study revealed a great deal about the planning and support necessary for implementing a distance professional degree program. Continued investigation of the program through the second year of the first cohort group and through the second and third cohort groups should provide additional detail to help us to better understand the phenomena as they emerge, as well as the essential conditions for success. As educational institutions attempt to respond to the needs and goals of potential learners, these conditions will become ever more significant for program planning and implementations. 


\section{REFERENCES}

1. Greco, JoAnn., Going the distance for MBA candidates, Journal of Business Strategy, vol. 20, no. 3, pp. 30-34, 1999.

2. Westbrook, T.S., \& Moon, D.K., Lessons learned from the delivery of a graduate business degree program utilizing interactive television, The Journal of Continuing Higher Education, vol. 45, no. 2, pp. 25-33, 1997.

3. Davis, S., What you need to know about distance learning, in Peterson's (ed.), MBA distance learning programs, Peterson's, Princeton, NJ, pp. 41-47, 1999.

4. Gerencher, K., MBA programs go online', InfoWorld, vol. 20, pp. 71-72, 1998.

5. Mangan, K. S., Top business schools seek to ride a bull market in on-line MBA's, The Chronicle of Higher Education, vol. 45, no. 19, pp. A27-A28, 1999.

6. National Center for Education Statistics (NCES), Distance education in higher education institutions: Incidence, audiences, and plans to expand, National Center for Education Statistics (NCES), http://nces.ed.gov/pubs98/98132.html February 1998 (Accessed 7 May 1999), 1998.

7. $\quad$ Peterson's., MBA distance learning programs, Peterson's, Princeton, NJ, 1999.

8. Schrum, L., On-line education: A study of emerging pedagogy, in B. Cahoon (ed.), Adult Learning and the Internet, Jossey-Bass Publishers, San Francisco, vol. 78, pp. 53-61, 1998.

9. Lincoln, Y. S., \& Guba, E. G., Naturalistic inquiry, Sage Publications, Newbury Park, CA, 1985.

10. Miles, M. B., \& Huberman, A. M., Qualitative data analysis, Sage Publications, Newbury Park, CA, 1985.

11. Patton, M. Q., How to use qualitative methods in evaluation, Sage Publications, Newbury Park, CA, 1987.

12. Schrum, L., Framing the debate: Ethical research in the information age, Qualitative Inquiry, vol. 1, no. 3, pp. 311-326, 1995.

13. Candiotti, A., \& Clarke, N., Combining universal access with faculty development and academic facilities, Communications of the ACM, vol. 41, no. 1, pp. 36-41, 1998.

14. Schlesinger, P. F., Teaching and evaluation in an integrative curriculum, Journal of Management Education, vol. 20, no. 4, pp. 479-499, 1996.

15. Watkins, T. L., Stage one: Creating a new MBA core with team teaching, Journal of Management Education, vol. 20, no. 4, pp. 411-421, 1996.

\section{ABOUT THE AUTHORS}

Lynne Schrum is an Associate Professor in Instructional Technology at The University of Georgia. Her research interests are in the areas of distance learning, technology integration and ethics in online research. Dr. Schrum is the immediate past President of the International Society for Technology in Education (ISTE).

Angela Benson is a doctoral student in Instructional Technology at The University of Georgia. Her research interests are in the areas of distance learning, technology integration, and instructional design. Angela is the current Chair of the Graduate Student Committee of the American Educational Research Association (AERA). 